\title{
Novel arginine end-tagging antimicrobial peptides to combat multidrug-resistant bacteria
}

Lu Shang ${ }^{1,2}$, Yuting $\mathrm{Wu}^{1,2}$, Nan Wei ${ }^{1,2}$, Fayu Yang ${ }^{1,2}$, Mi Wang ${ }^{1,2}$, Lifang Zhang ${ }^{1,2}$, Chenzhong $\mathrm{Fei}^{1,2}$, Yingchun Liu ${ }^{1,2}$, Feiqun Xue ${ }^{1,2}$, Feng Gu ${ }^{1,2, *}$

${ }^{1}$ Shanghai Veterinary Research Institute, Chinese Academy of Agricultural Sciences, Shanghai 200241, China

${ }^{2}$ Key Laboratory of Veterinary Chemical Drugs and Pharmaceutics, Ministry of Agriculture and Rural Affairs, Shanghai 200241, China

*Correspondence: Feng Gu, 518 Ziyue Road, Minhang District, Shanghai 200241, China. E-mail address: fgu@shvri.ac.cn. 

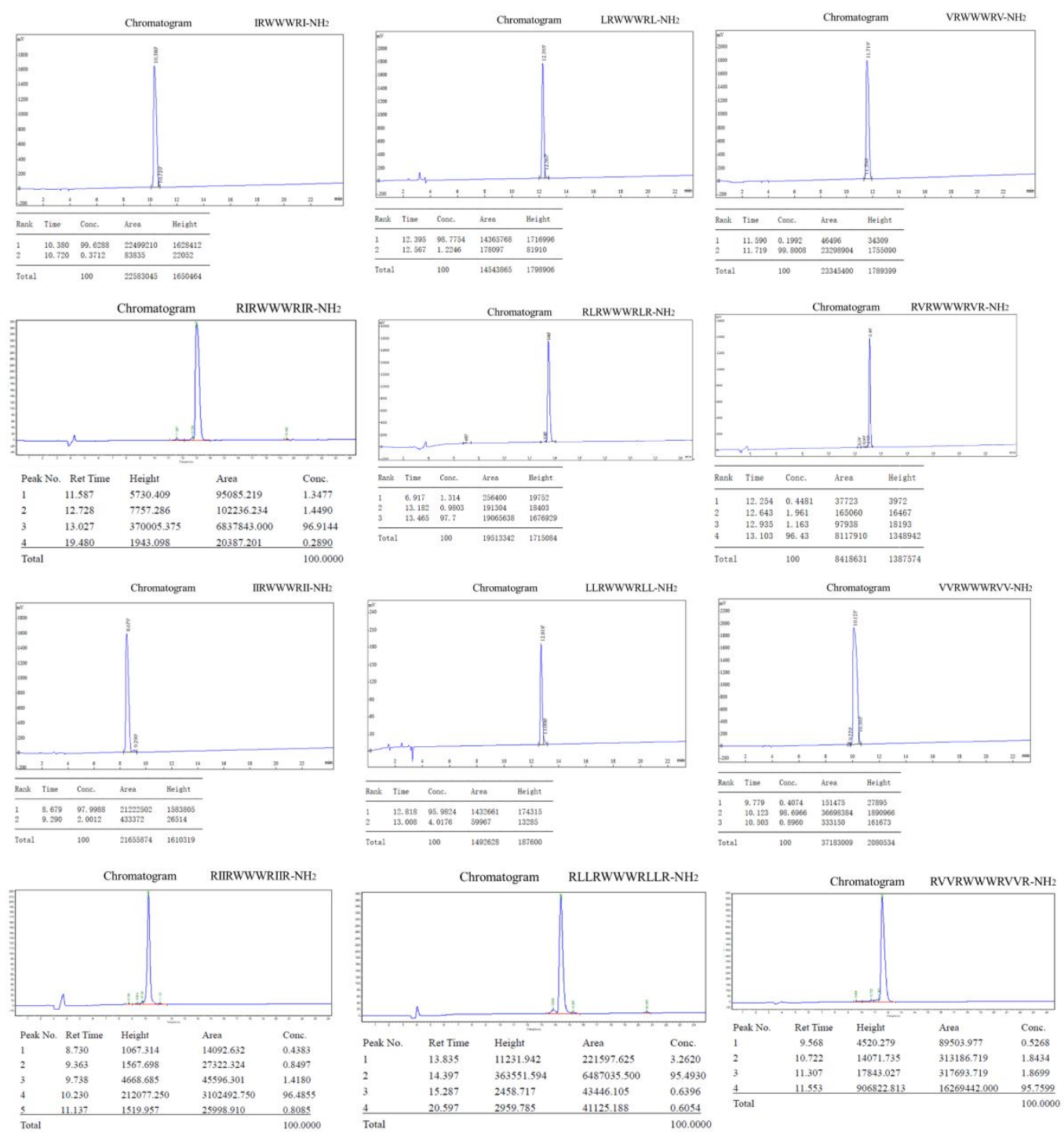

Figure S1. Reverse-phase high-performance liquid chromatography (RP-HPLC) of the peptides in this study. 

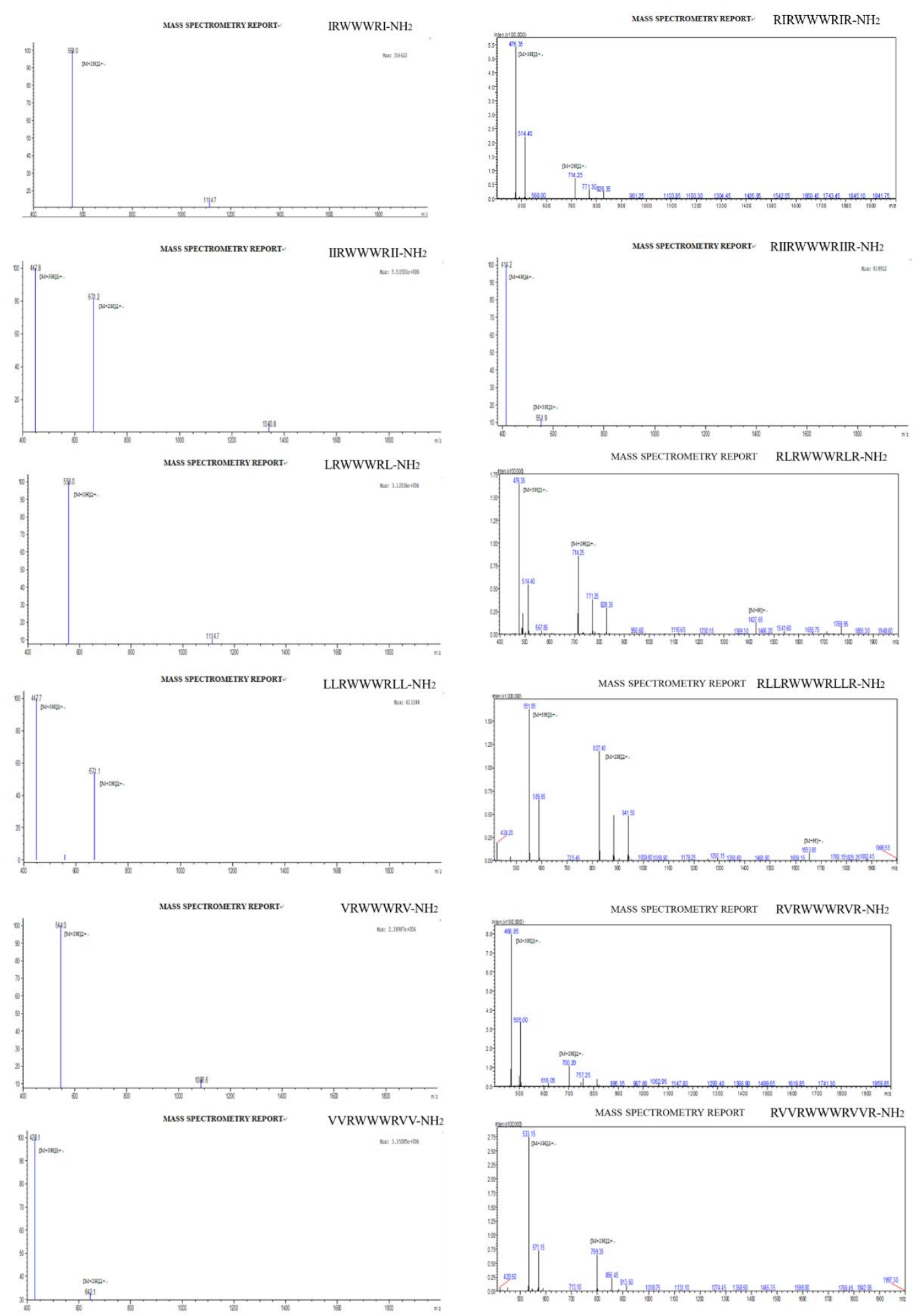

Figure S2. Matrix-assisted laser desorption/ionization time-of-flight mass spectrometry (MALDI-TOF MS) of the peptides in this study. 
a

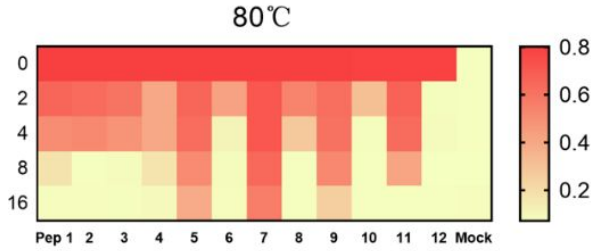

b
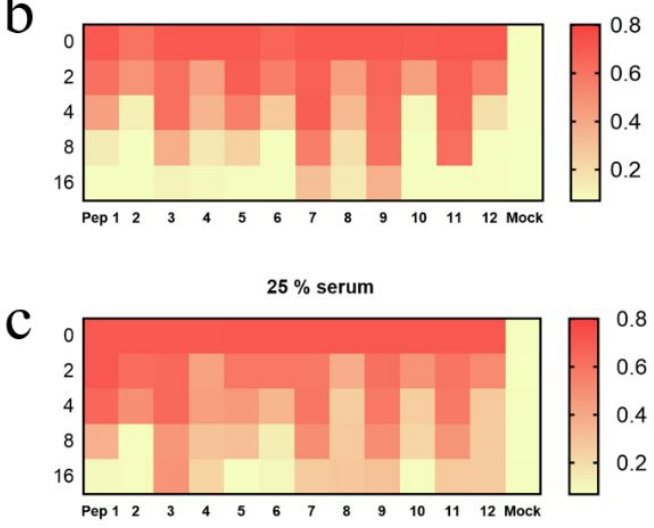

$80^{\circ} \mathrm{C}$

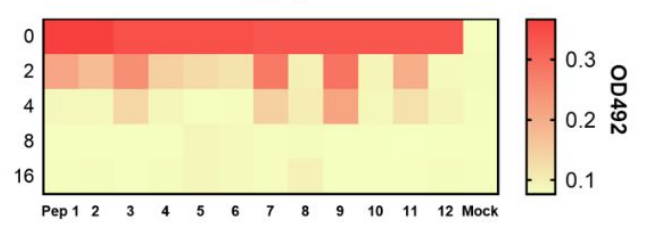

$50 \%$ serum

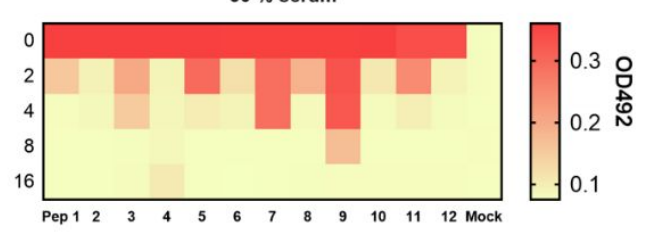

$25 \%$ serum

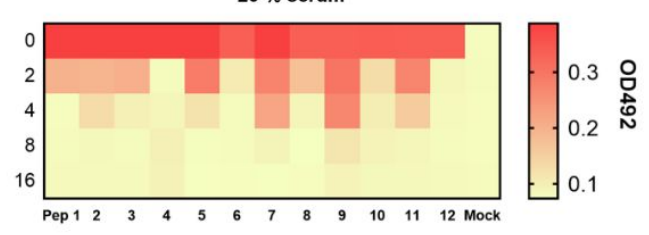

Figure S3. The stability of the peptides. (a) Peptides were treated at $80^{\circ} \mathrm{C}$ for one hour and then tested antibacterial activity against $E$. coli (left) and S. aureus (right). (b) Antimicrobial activity of peptides against $E$. coli (left) and $S$. aureus (right) in the presence of $50 \%$ serum. (c) Antimicrobial activity of peptides against E. coli (left) and S. aureus (right) in the presence of $25 \%$ serum. 

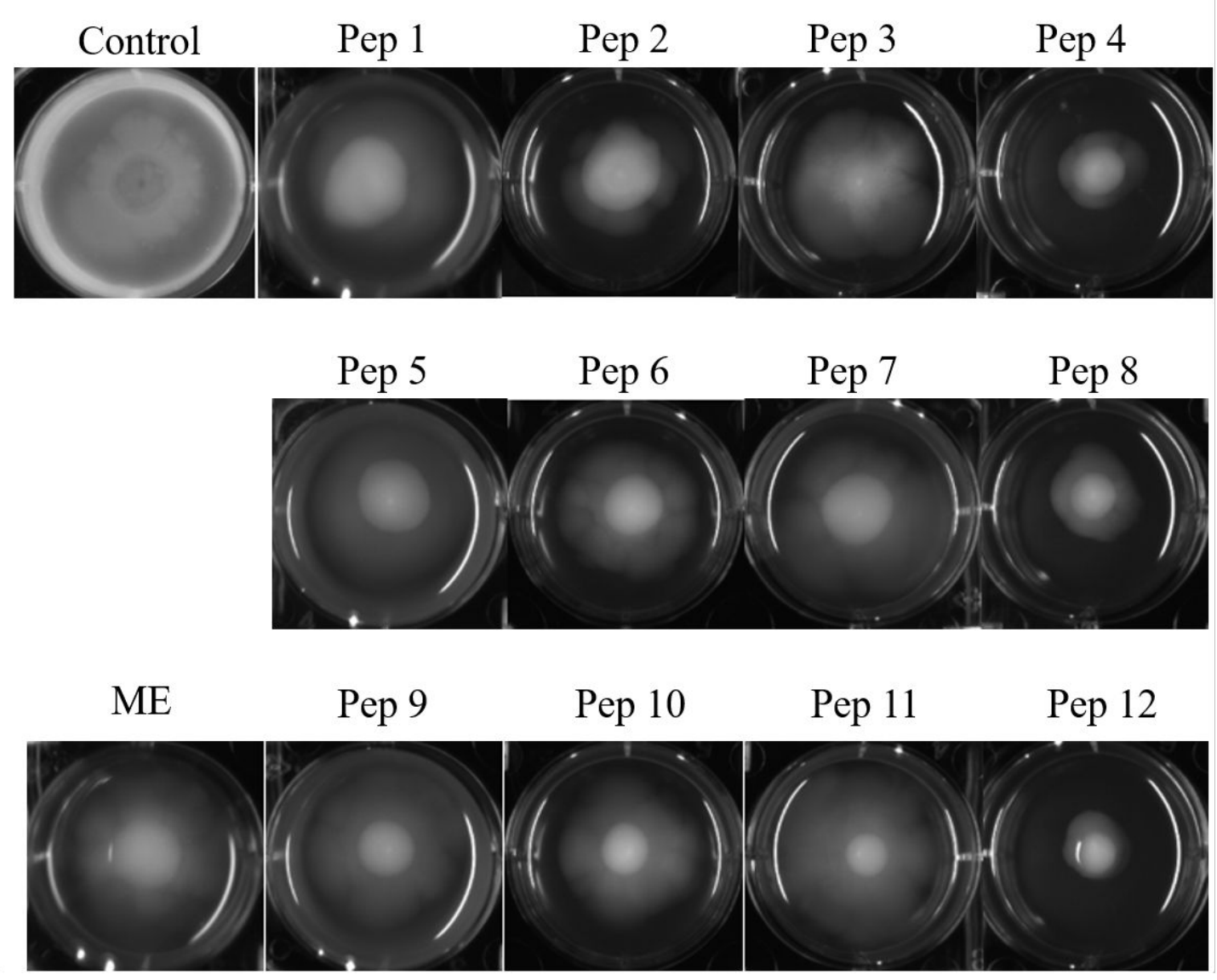

Figure S4. Swimming motility of E. coli 25922 treated with peptides. Melittin(ME) as a control. 
a

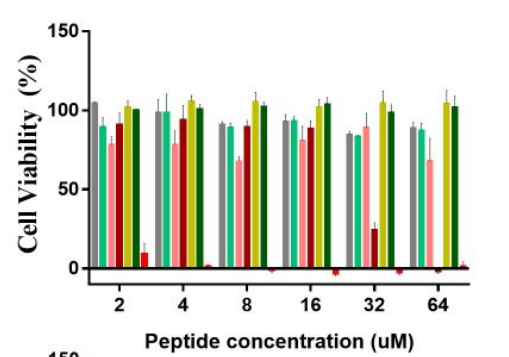

b

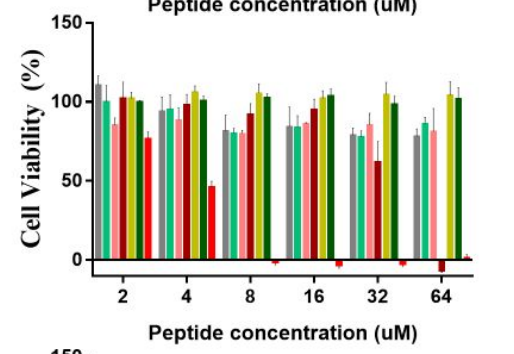

C

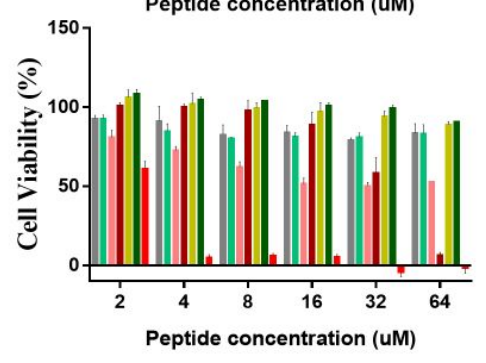

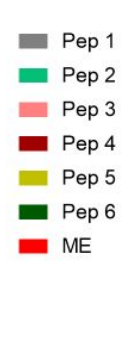
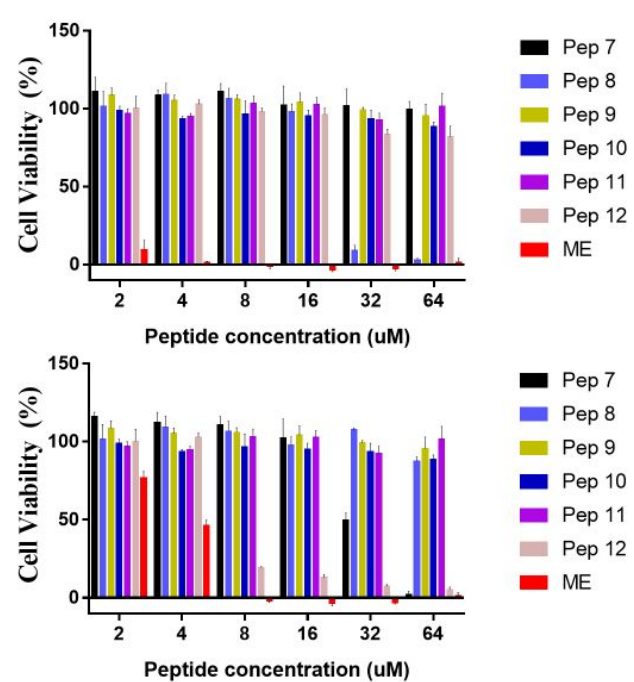

- Pep 1

- Pep 2

- Pep 3

- Pep 4

- Pep 5

- Pep 6

- ME

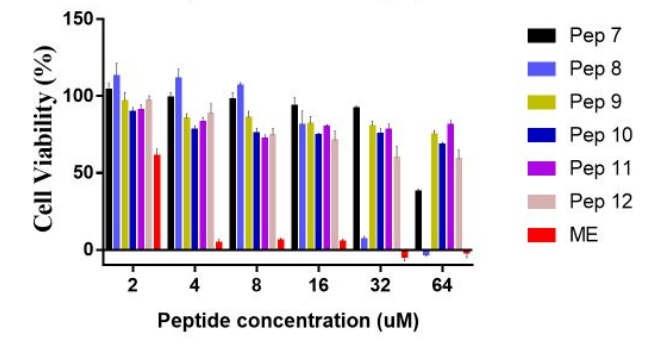

Figure S5. Cytotoxicity of the peptides in different cell lines. Cell viability with the peptides treatment in (a) RAW 264.7, (b) HEK-293, and (c) Vero cells for $24 \mathrm{~h}$. Melittin (ME) as a control. 


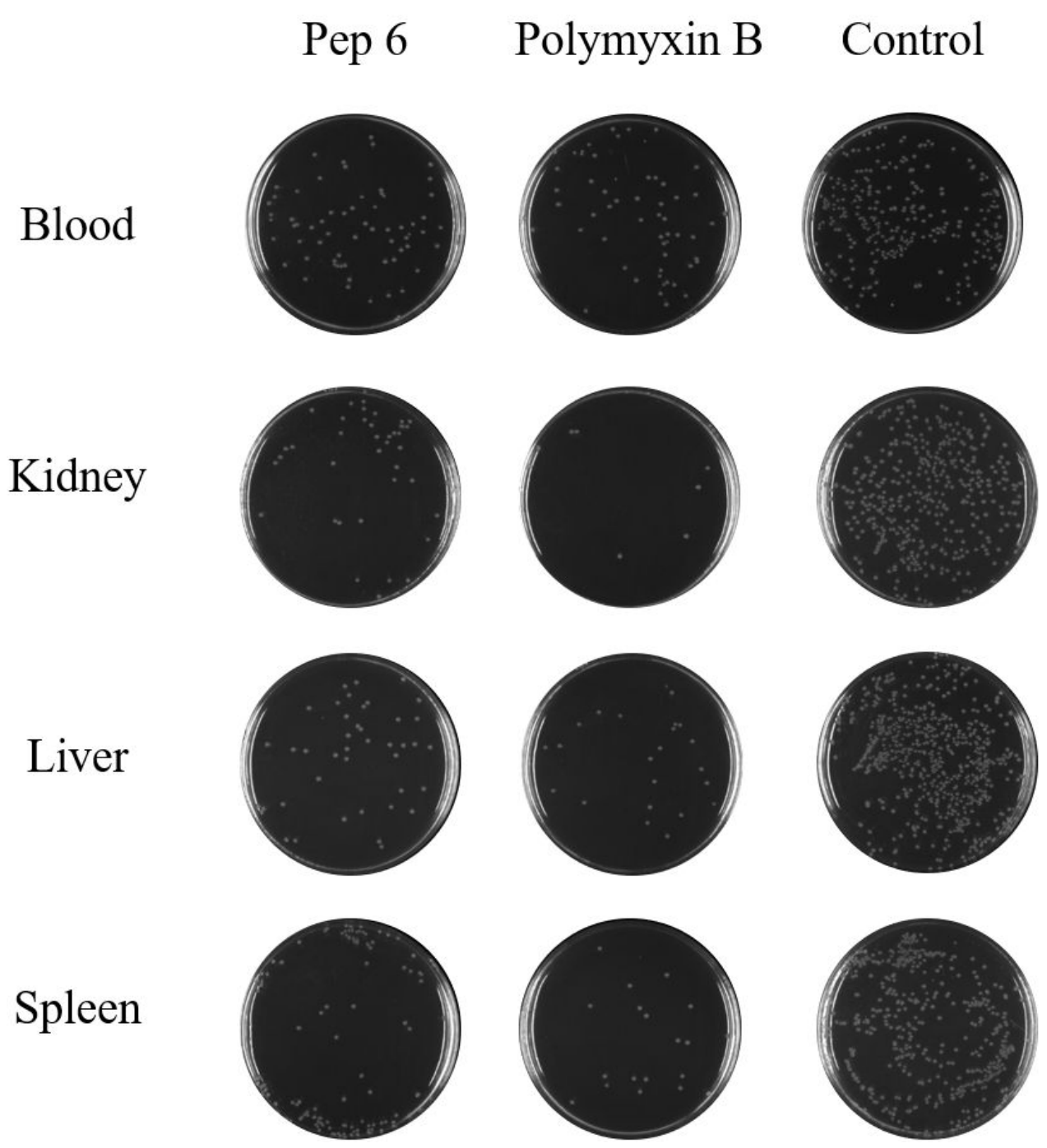

Figure S6. Bacterial burden in blood, kidney, liver, and spleen of infected mice with different treatments. Polymyxin B as a control. 